more potent statements. I am sceptical about unreferenced statements. The reader will findchapter 11 (specific strength training programmes) a nice inclusion and one that could even be expanded further. Other novel topics include functional isometrics and hormonal adaptation to resistance training.

In summary, Dr O'Shea has done a nice job. I do believe, however, that in its current form the text has greater applicability for the more advanced participant. It will provide an excellent source of information and resource for training ideas and programme formulation. It is also good value for money. The reader is unlikely to come across a text written by an author with as much practical and theoretical insight in the area of resistance training as $\mathrm{Dr}$ O'Shea.

DECLAN CONNOLLY

Bangor

\section{Sports and Exercise Medicine: Policy} and Provision. (Pp 48; £6.95.) London: BMJ Publishing Group, 1996. ISBN 07279 10956.

Many doctors in Britain do not have enough knowledge to advise patients on how to play sport safely or to treat them if they become injured, says a new report published by the BMA's board of science and education. Sport and exercise medicine: policy and provision says that a faculty of sport and exercise medicine should be created, that the provision of sports medicine facilities should be reviewed, and that athletes need better education on how to avoid injuries.

There are about 19 million sports injuries in England and Wales each year, about half of them are in people aged 16 to 25 years of age. Injuries are more common when the sport is competitive, with sports such as rugby, football, and hockey carrying the highest risks. As many as three fifths of new injuries are caused by collisions between players.

The skill and knowledge of doctors have an important effect on how well people recover from injuries; however, the NHS has no training structure for doctors in sports medicine. Thus a faculty of sports medicine should be established to set standards for postgraduate training and accreditation and sports medicine should be included in the undergraduate curriculum, says the report. It also emphasises the important role of doctors with existing expertise in sports medicine: sports medicine specialists should help sporting bodies to reduce the number of injuries by advising them about rules and regulations to improve safety.

The report asks the government to develop policy for the provision of services for sports injuries and suggests a national network of sports medicine centres with a standard system of accreditation. It sets out guidelines for such centres which should provide education for athletes and coaches on how to avoid injuries as well as treating people when injuries do happen.

If campaigns to increase the level of activity of the population are successful, even more people will be at risk of injury; thus the promotion of physical activity must be backed up by strategies to minimise these. Doctors who promote physical activity should know about the risks and ensure that medical services are provided. The report calls for clearer exercise targets to help both the public and doctors know what levels they should be aiming for. Emphasis should be placed on moving individuals from the sedentary category to moderate levels of activity-a theme which is repeated in the Health Education Authority's guide

S J LOUISE SMITH Edinburgh

\section{Promoting Physical Activity in Primary}

Health Care. Health Education Authority. (Pp 31+10 inserts; 66.99 .) Abingdon: HEA Customer Services. ISBN 0752102893.

Primary health care teams are urged to encourage their patients to take more exercise by a new Health Education Authority (HEA) guide. Promoting physical activity in primary health care is part of a three year campaign by the HEA, which says that six out of 10 men and seven out of 10 women are not active enough to benefit their health. The guide discusses how to develop a physical activity promotion programme and how to help patients become more active by giving opportunistic advice, counselling, and developing effective exercise prescription and referral schemes.

Traditionally, people have been advised to do 20 minutes of "vigorous" exercise three times a week. Moving away from this dogma, the HEA now recommends 30 minutes of "moderate"activity, such as washing the car, heavy housework, or gardening, five times a week. Advice such as this, with easy to understand examples, may go some way to answering the BMA's call for practical exercise targets against which individuals can assess whether they are active enough.

A common reason for not exercising is the problem of finding time, so activities which can be incorporated into a daily routine such as walking to work rather than driving are emphasised by this guide. Patients should not be discouraged by being told that the activity they are taking may not benefit their health, even if it is not of the maximum level, says the guide. Notably the guide refers to physical activity and not to exercise.

Patients who are contemplating starting to exercise or doing some exercise occasionally are identified as the groups that are the most profitable to work with. For these selected groups of patients it suggests approaches such as "prescription schemes". Alternative suggestions include links with community based classes, setting up a class for patients, and even taking your patients with you when you go for your own run or cycle. Thankfully, the authors acknowledge that this final approach may not suit everyone.

The potential risks of exercise, such as sudden cardiac death and musculoskeletal injury, along with the legal liabilities for doctors, are carefully covered. General practitioners must carry full clinical responsibility for the patients whom they refer for exercise. In Sport and exercise medicine: policy and provision the BMA also states that those who promote physical activity should be aware of the relevant risks and ensure that appropriate medical facilities are available. Full assessment of each patient and knowing what activities are provided by each exercise venue are essential, says the HEA. However, the guide concludes that for most people sensible exercise offers more benefits than risks. Physical exercise could be the "best buy" for public health in developed countries.

S J LOUISE SMITH Edinburgh
Sports Psychology in Action. By Richard J Butler. (Pp 144; paperback $£ 14$.99.) Oxford: Butterworth Heinemann, 1996. ISBN 07506 24361.

To those working in the field of applied sport psychology in the United Kingdom, Richard Butler's name will be both familiar and well respected. Coming from a background in clinical psychology, he has worked successfully with a number of sports but most especially amateur boxing.

Those working in sport psychology will also be too well aware of the chasm which has often separated the world of competitive sport inhabited by practising sport psychologists from the ivory towers populated by research sport psychologists. If this book is about anything, probably it is about helping to build a bridge over those troubled waters. In achieving this goal it is largely successful and it is easy to see the book being used by applied sport psychologists in the course of their work.

Performance profiling and the development of the athlete's self awareness are generally regarded as the linchpin of a successful intervention strategy, and it is these topics, close to the heart of Butler's own research interests, which from the focus of the early part of the book. Liberally sprinkled with quotes from sportspeopIe and coaches, chapters 2 to 4 take the reader easily through useful practical techniques, and later chapters often continue the theme of developing awareness. For example, chapter 7, on "feelings", considers various mood profiles of athletes using a device known as the feelings scale, presumably developed by the author. Familiar topics such as stress management, concentration and attention, self confidence, and visualisation make an appearance later, where again the emphasis is on the practical delivery of information to performers but set in the context of relevant theory and literature.

An overriding theme throughout is that mental training should not be divorced from physical or technical training, and that all should merge seamlessly together in an holistic approach to strategic interventions with sportspeople. This is a very important message and one which cannot be overemphasised. While the book is said to be aimed at a very broad audience, my guess would be that it may be a little beyond the average layperson but will be enjoyed immensely by those already familiar with the area, or other sport sciences, and it will be regarded as a valuable contribution to the literature.

JOHN KREMER Belfast

\section{NOTES AND NEWS}

\section{The British Association of Sport and}

\section{Medicine Congress Award}

In this issue we have published as many of the abstracts from the BASM Annual Congress as can fit the allotted space. No implications about quality are attached to the abstracts which we unfortunately were unable to publish for lack of space. A prize is to be awarded for what was judged to be the best oral presentation and the best poster. This is to be known as "The British Association of Sport and Medicine Congress Award". 